\title{
MENENTUKAN KOMBINASI OPTIMAL PARAMETER COFFEE ROASTING UNTUK MENDAPATKAN ROASTED BEAN DENGAN TINGKAT KEMATANGAN MEDIUM ROAST MENGGUNAKAN METODE TAGUCHI
}

\author{
Arya Anantama R., Nia Budi Puspitasari, Ary Arvianto*) \\ Program Studi Teknik Industri Fakultas Teknik - Universitas Diponegoro \\ JL. Prof. Soedarto, SH Tembalang Semarang 50239
}

\begin{abstract}
Abstrak
Penelitian dilakukan dengan Metode Taguchi untuk menentukan kombinasi optimal dari parameter coffeeroasting. Parameter yang diteliti adalah lamanya waktu roasting sebagai faktor A dan volume biji total untuk sekali proses roasting sebagai faktor B.Eksperimen dilakukan dengan tiga level dan tiga nilai untuk masing-masing faktor. Dari hasil Eksperimen Taguchi didapatkan bahwa level faktor yang memberikan pengaruh yang signifikan terhadap roasted bean adalah faktor A pada level 2 dan faktor B pada level 1. Berdasarkan nilai rata-rata roastedbean dan nilai SNR yang dihasilkan, terlihat bahwa faktor A2 (75 menit) dan faktor B1 (2 kg) menghasilkan nilai rata-rata roasted bean sesuai dengan nilai yang dituju. Eksperimen Konfirmasi dilakukan dengan menggunakan parameter yang dianggap terbaik. Hasil Eksperimen Konfirmasi menunjukkan kombinasi fakor A2 dengan B1 merupakan kombinasi yang optimal untuk mendapatkan roasted bean kualitas premium.
\end{abstract}

Kata Kunci : coffee roasting; kopi, taguchi; roasted bean

\begin{abstract}
The research is done using Taguchi Method to determine optimum combination of coffee roasting parameters. These parameters consist of roasting time as factor A and total volume of every roasting process as factor B.Experiment is conducted within three levels and three values for each factor. Taguchi Method result shows that significant influence toward roasted bean comes from level 2 on factor $A$ and level 1 on factor B. Based on average value of roasted bean and SNR value, factor A2 (75 minutes) and factor B1 (2 $\mathrm{kg}$ ) produced average value of roasted bean in accordance to set value. Confirmation experiment is performed with parameters that are most suitable. The result of confirmation experiment shows combination of $A 2$ and B1 as optimum combination to exercise premium quality roasted bean.
\end{abstract}

Keyword : coffee roasting; coffe; taguchi; roasted bean

\section{Pendahuluan}

Saat ini minum kopi sudah menjadi menjadi bagian dari gaya hidup orang di seluruh dunia termasuk Indonesia. Kementrian Perindustrian Republik Indonesia tahun 2012 menyebutkan bahwa Indonesia merupakan negara penghasil kopi terbesar ketiga dunia setelah Brasil dan Vietnam. Di provinsi Jawa Tengah sendiri khususnya Kabupaten Semarang memiliki sejumlah perkebunan kebun kopi rakyat, salah satunya adalah perkebunan kopi rakyat yang ada di Dusun Jeruk Wangi.

Sebelum dapat dikonsumsi sebagai minuman, biji kopi harus melalui 3 proses utama yaitu roasting

\footnotetext{
${ }^{*}$ Penulis Korespondensi. email: aryarvi@yahoo.com
}

(menyangrai biji kopi), grinding (menghaluskan biji kopi), dan brewing (menyeduh bubuk kopi) (Folmer, 2014).

Saat ini produksi kopi lokal disekitar perkebunan rakyat masih menggunakan metode tradisional, yaitu dengan menggunakan bejana terbuka seperti wajan tanah liat sehingga hasil produksi tidak optimal. Untuk mendapatkan hasil produksi kopi lokal yang optimal dapat menggunakan mesin sangrai tabung. Namun, untuk saat ini belum ada kombinasi yang paling optimal dari faktor-faktor yang ada dalam proses roasting untuk mendapatkan hasil sangrai (roasted bean) kualitas premium. Untuk meningkatkan kualitas roasted bean pada penelitian ini menggunakan Metode Taguchi. Penelitian ini bersifat eksperimental, dengan tujuan untuk mengetahui perubahan hasil sangrai kopi skala rumahan ketika diperlakukan dengan eksperimen yang berbeda-beda. Harapannya adalah hasil sangrai kopi 
skala rumahan ini dapat meningkat kualitasnya. Sangrai kopi yang menggunakan alat otomatis (sudah memakai mesin) biasa dipakai industri kopi skala pabrik untuk mencapai tingkat kualitas tertentu, sedangkan dalam penelitian ini menggunakan alat yang biasa dipakai industri kopi namun dalam skala rumahan (tanpa mesin otomatis) dengan maksud yang sama yaitu mampu meningkatkann kualitas kopi yang lebih baik. Secara fungsi alat yang digunakan pada penelitian, telah mewakili aspek-aspek yang dibutuhkan dalam memproses produk biji kopi sesuai eksperimen yang dilakukan.

\section{Metodologi Penelitian}

Urutan proses secara lengkap yang dilalui dalam melakukan penelitian ini dirumuskan kedalam suatu flowchart Gambar 1. Untuk mendapatkan hasil eksperimen yang valid serta untuk menekan noise, maka dilakukan hal-hal berikut pada setiap eksperimen

a) Eksperimen dilakukan di ruangan dengan sirkulasi udara bagus dan memiliki temperatur ruangan un- tuk memastikan bahwa ruang tersebut suhunya stabil.

b) Ukuran diseleksi menggunakan kawat ram untuk mendapatkan ukuran biji yang relatif sama.

c) Karena mesin belum memiliki termometer maka untuk memastikan suhu roasting setiap eksperimen sama, katup gas diatur sama untuk setiap eksperimen..

d) Setelah proses roasting selesai maka roast bean langsung diletakkan diatas nampan bambu kemudian didinginkan menggunakan kipas angin dengan kecepatan yang sama untuk setiap eksperimennya.

e) Untuk memastikan proses berjalan lancar eksperimen dilakukan dengan menggunakan gas baru untuk setiap eksperimen, serta eksperimen dilakukan maksimal 1 kali dalam 1 hari dengan operator yang sama untuk setiap eksperimen.

f) Setiap eksperimen dilakukan sebanyak 12 kali, kemudian diambil 6 eksperimen yang memiliki hasil mendekati untuk dimasukkan dalam Tabel Data Hasil Percobaan Coffee Roasting sebagai hasil replikasi sebanyak 6 kali.

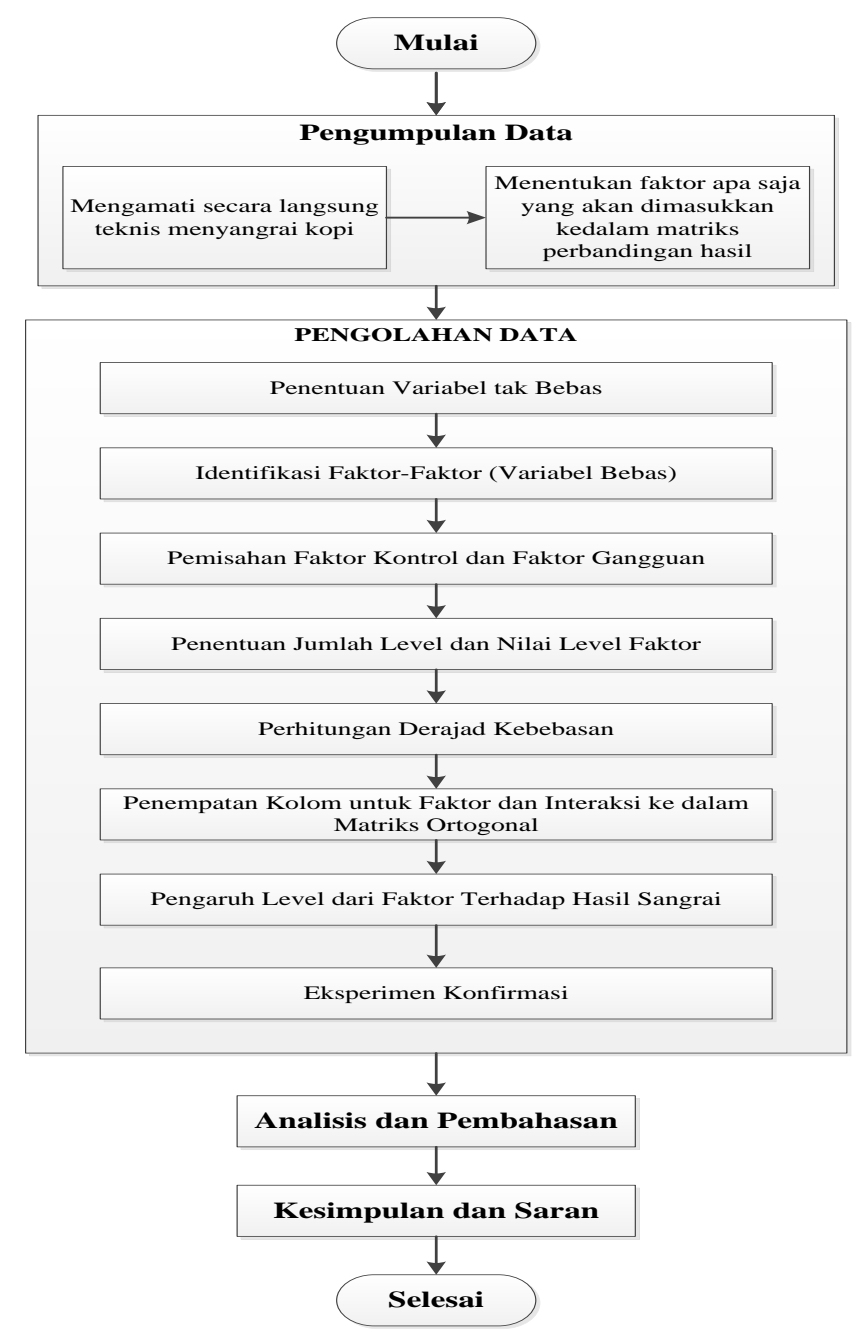

Gambar 1. Tahapan Penelitian 


\section{Hasil Ekperimen}

\section{Penentuan Variabel tak Bebas}

Variabel tak bebas (faktor noise) adalah faktorfaktor yang nilainya tidak dapat diatur atau dikendalikan, walaupun dapat diatur faktor noise akan mahal biayanya (Soejanto dan Irwan. 2009).

Dalam penelitian ini yang termasuk dalam variabel bebas adalah suhu lingkungan (suhu diluar mesin/eksternal).

\section{Identifikasi Faktor-Faktor (Variabel Bebas)}

Variabel bebas (faktor terkontrol) adalah faktorfaktor yang nilainya dapat diatur atau dapat dikendalikan oleh peneliti dalam melakukan penelitian (Soejanto, Irwan, 2009).

Dalam penelitian ini variabel bebas yang akan diamati adalah lamanya waktu roasting (sangrai) dan volume biji total untuk sekali proses roasting, karena kedua faktor tersebut dianggap paling berpengaruh terhadap hasil akhir yaitu roasted bean.

\section{Penentuan Jumlah Level dan Nilai Level Faktor}

Setiap faktor terkontrol memiliki tiga level, dan nilai dari masing-masing level faktor tekontrol dapat dilihat pada Tabel 1 .

Tabel 1. Perubahan Nilai Level Faktor terkontrol

\begin{tabular}{lccc}
\hline \multirow{2}{*}{ Faktor } & \multicolumn{3}{c}{ Level } \\
\cline { 2 - 4 } & 1 & 2 & 3 \\
\hline $\begin{array}{l}\text { A. Lamanya roasting } \\
\text { (menit) }\end{array}$ & 30 & 75 & 90 \\
B. Volume biji total (kg) & 2 & 6 & 10 \\
\hline
\end{tabular}

Faktor yang akan dileliti adalah lamanya roasting, dan volume total biji, karena kedua faktor tersebut dianggap paling berpengaruh terhadap hasil akhir yaitu roasted bean.

Lamanya roasting berpengaruh terhadap tingkat kematangan roasted bean apakah light, medium, atau dark (Schenker, S., et al.,. 2002).

Volume total biji berpengaruh terhadap efisiensi alat, karena lamanya roasting ditentukan oleh volume total biji dalam sekali proses roasting. Nilai level faktor didapatkan dari penelitian yang sudah ada sebelumnya dan pengamatan langsung proses sangrai kopi menggunakan mesin sangrai untuk industri kopi rumahan.

\section{Perhitungan Derajad Kebebasan}

Pada penelitian ini faktor terkontrol yang diamati adalah sejumlah 3 faktor dengan masing-masing faktor terdiri dari 3 level. Dengan adanya faktor A, B, serta interaksi $\mathrm{AxB}$ (karena faktor $\mathrm{A}$ dapat mempengaruhi faktor B, dan sebaliknya), maka derajad kebebasan total yang terbentuk adalah (Soejanto, Irwan. 2009):
Tabel 2. Perhitungan Derajad Kebebasan Total

\begin{tabular}{clc}
\hline Faktor & \multicolumn{1}{c}{ Derajad Kebebasan } & Total \\
\hline A & $(3-1)$ & 2 \\
B & $(3-1)$ & 2 \\
AxB & $(3-1) \times(3-1)$ & 4 \\
\hline & Total Derajad Kebebasan & 8 \\
\hline
\end{tabular}

Penempatan Kolom untuk Faktor dan Interaksi ke dalam Matriks Ortogonal

Pemilihan Orthogonal Array berdasarkan pengamatan yang diambil melalui pemilihan faktor kualitas dan level yang sering mempengaruhi roasted bean, maka Orthogonal Array yang dipakai adalah : $L_{\mathrm{q}}\left(3^{4}\right)$ (Belavendram,1995)

Untuk memasukkan faktor dan interaksi kedalam kolom matrik ortogonal digunakan grafik linear $L_{q}\left(3^{4}\right)$ (Soejanto et al., 2009).

Dari grafik linier $L_{9}\left(3^{4}\right)$ tersebut dapat diketahui bahwa faktor A ditempatkan pada kolom 1, faktor B ditempatkan pada kolom 2, dan faktor AxB ditempatkan pada kolom 3 dan 4.

Tabel 3. Matriks Ortogonal $L_{9}\left(3^{4}\right)$

\begin{tabular}{ccccc}
\hline \multirow{2}{*}{ Eksperimen } & 1 & 2 & 3 & 4 \\
1 & $\mathrm{~A}$ & $\mathrm{~B}$ & $\mathrm{AxB}(1)$ & $\mathrm{AxB}(2)$ \\
2 & 1 & 1 & 1 & 1 \\
3 & 1 & 2 & 2 & 2 \\
4 & 1 & 3 & 3 & 3 \\
5 & 2 & 1 & 2 & 3 \\
6 & 2 & 2 & 3 & 1 \\
7 & 2 & 3 & 1 & 2 \\
8 & 3 & 1 & 3 & 2 \\
9 & 3 & 2 & 1 & 3 \\
\hline
\end{tabular}

Identifikasi Pengaruh Faktor Terhadap Rata-Rata

Data didapatkan dari percobaan yang dilakukan berdasarkan orthogonal array yang sudah dibuat. Level faktor yang digunakan dapat dilihat pada Tabel 1, Hasil eksperimen ditampilkan pada Tabel 4. Hasil dari eksperimen yang telah di pooling up dapat dilihat pada Tabel 5,

\section{Identifikasi Pengaruh Faktor/Interaksi Faktor Terhadap Variasi}

Dari hasil identifikasi pengaruh faktor terhadap rata-rata, dilakukan trasformasi data menjadi rasio $\mathrm{S} / \mathrm{N}$ (Chamoli dan Sunil, 2015).

Untuk dapat melihat lebih jelas pengaruh atau efek tiap faktor terhadap nilai rasio S/N (SNR). Hasil dari perhitungan ANOVA SNR yang telah di pooling up dapat dilihat pada Tabel 6 


\section{Perhitungan Persentase Kontribusi (Percent Con- tribution)}

Hasil perhitungan persen kontribusi seluruh faktor/interaksi yang berpengaruh pada rata-rata roastedbean diperlihatkan pada Tabel 7 , sedangkan untuk persen kontribusi pengaruh faktor terhadap variasi ditunjukkan pada Tabel 8, diketahui persentase kontribusi terbesar pada pencapaian rata - rata karakteristik kualitas adalah faktor A (waktu roasting), yang artinya waktu roasting memberikan kontribusi sebesar $50.32 \%$ terhadap pencapaian rata-rata kualitas.

\section{Eksperimen Konfirmasi}

Eksperimen konfirmasi dilakukan dengan menggunakan level faktor yang dianggap akan memberikan perbaikan kualitas yang diinginkan, yaitu dengan menggunakan kombinasi level faktor terbaik yang dapat meningkatkan kualitas roasted bean (Shailesh, P. et al., 2014).

Pada eksperimen konfirmasi, faktor dan level ditetapkan pada kondisi optimal yaitu waktu roasting 75 menit $\left(\boldsymbol{A}_{2}\right)$ dan volume biji total $2 \mathrm{~kg}\left(\boldsymbol{B}_{\mathbf{1}}\right)$.

\section{Pembahasan}

Dari hasil perhitungan selang kepercayaan pada tingkat kepercayaan $95 \%$ untuk eksperimen taguchi kemudian dibandingkan dengan selang kepercayaan untuk eksperimen konfirmasi didapat bahwa rata-rata pada eksperimen konfirmasi berada pada selang kepercayaan eksperimen taguchi. Selang kepercayaan tersebut dapat dilihat pada tabel 9 .

Eksperimen taguchi ke eksperimen konfirmasi mengalami penurunan pada rata-rata hasil roasting atau roasted bean-nya dan peningkatan pada nilai variabilitas roasted bean-nya. Dengan demikian kombinasi optimal faktor-faktor tersebut diatas terbukti dapat meningkatkan hasil roasted bean. Namun penurunan yang terjadi pada nilai rata-rata dan peningkatan pada nilai variabilitas selisihnya tidak jauh, dengan kata lain masih dalam rentang nilai yang diharapkan (karena nilai rata-rata dan variabilitas sudah ditentukan sebelumnya), sehingga dapat ditarik kesimpulan bahwa kombinasi faktor yang optimal adalah faktor A (waktu roasting) pada level 2 yaitu roasting selama 75 menit dengan faktor B (volume total biji pada level 1 yaitu volume biji total seberat $2 \mathrm{~kg}$.

Tabel 4. Hasil Eksperimen

\begin{tabular}{|c|c|c|c|c|c|c|c|c|c|c|c|c|}
\hline \multirow{3}{*}{ Trial } & \multicolumn{10}{|c|}{ Matriks Othogonsl Array $L 9\left(3^{4}\right)$} & \multirow{3}{*}{ Jumlah } & \multirow{3}{*}{ Mean } \\
\hline & \multicolumn{4}{|c|}{ Faktor Kontrol } & \multicolumn{6}{|c|}{ Replikasi } & & \\
\hline & A & $\mathrm{B}$ & $\mathrm{AxB}(1)$ & $\mathrm{AxB}(2)$ & 1 & 2 & 3 & 4 & 5 & 6 & & \\
\hline 1 & 1 & 1 & 1 & 1 & 7 & 6 & 6 & 7 & 8 & 8 & 42 & 7.00 \\
\hline 2 & 1 & 2 & 2 & 2 & 5 & 4 & 3 & 5 & 5 & 5 & 27 & 4.50 \\
\hline 3 & 1 & 3 & 3 & 3 & 4 & 4 & 5 & 4 & 3 & 3 & 23 & 3.83 \\
\hline 4 & 2 & 1 & 2 & 3 & 15 & 14 & 16 & 13 & 13 & 16 & 87 & 14.50 \\
\hline 5 & 2 & 2 & 3 & 1 & 10 & 11 & 13 & 13 & 12 & 11 & 70 & 11.67 \\
\hline 6 & 2 & 3 & 1 & 2 & 9 & 7 & 11 & 8 & 10 & 7 & 52 & 8.67 \\
\hline 7 & 3 & 1 & 3 & 2 & 14 & 14 & 15 & 15 & 16 & 14 & 88 & 14.67 \\
\hline 8 & 3 & 2 & 1 & 3 & 12 & 15 & 11 & 13 & 14 & 15 & 80 & 13.33 \\
\hline 9 & 3 & 3 & 2 & 1 & 11 & 13 & 11 & 11 & 11 & 12 & 69 & 11.50 \\
\hline \multicolumn{12}{|c|}{ Rata - rata } & 9.96 \\
\hline
\end{tabular}

Tabel 5. Hasil Pooling Faktor

\begin{tabular}{crrrrr}
\hline Faktor & \multicolumn{1}{c}{ SS } & dof & MS & F hitung & F tabel \\
\hline A & 109.56 & 2 & 54.78 & 188.82 & 4.10 \\
B & 24.75 & 2 & 12.37 & 42.65 & 4.10 \\
Error & 2.90 & 10 & 0.29 & & \\
\hline Total & 137.21 & 14 & & &
\end{tabular}

Maka faktor-faktor dan interaksi faktor yang berpengaruh pada rata-rata hasil roasted bean adalah :

Faktor A = Faktor lamanya roasting

Faktor B = Faktor volume total biji 
Tabel 6. Analisis Variansi Signal Noise Ratio

\begin{tabular}{cccccc}
\hline Faktor & SS & dof & MS & F & F tabel \\
\hline A & 63.84 & 2 & 31.92 & 13.22 & 3.74 \\
B & 29.27 & 2 & 14.64 & 6.06 & 3.74 \\
Error & 24.15 & 10 & 2.41 & & \\
\hline Total & 117.25 & 14 & & & \\
\hline
\end{tabular}

Maka faktor - faktor yang berpengaruh pada rata - rata hasil roasted bean adalah :

Faktor $\mathrm{A}=$ Waktu roasting

Faktor B $=$ Volume biji total

Tabel 7. Persen Kontribusi Rataan

\begin{tabular}{crcccc}
\hline Faktor & \multicolumn{1}{c}{ SS } & dof & MS & \multicolumn{1}{c}{ SS } & $\rho$ \\
\hline A & 109.56 & 2 & 54.78 & 108.98 & $7.94 \%$ \\
B & 24.75 & 2 & 12.37 & 24.17 & $17.61 \%$ \\
Error & 2.90 & 10 & 0.29 & & \\
\hline
\end{tabular}

Total $\quad 137.21 \quad 14$

Tabel 8. Persen Kontribusi S/N

\begin{tabular}{cccccc}
\hline Faktor & SS & dof & MS & \multicolumn{1}{l}{ SS' } & P \\
\hline A & 63.84 & 2 & 31.92 & 59.01 & $50.32 \%$ \\
B & 29.27 & 2 & 14.64 & 24.44 & $20.84 \%$ \\
error & 24.15 & 10 & 2.41 & & \\
\hline Total & 117.25 & 14 & & & \\
\hline
\end{tabular}

Tabel 9. Interpretasi Hasil Ukur Roasted Bean

\begin{tabular}{llrc}
\hline \multicolumn{2}{c}{ Roasted Bean } & Prediksi & \multicolumn{1}{c}{ Optimasi } \\
\hline \multirow{2}{*}{ Eksperimen taguchi } & Rata-rata & 13.90 & $13.90 \pm 0.76$ \\
& Variabilitas (S/N) & 23.30 & $23.30 \pm 1.75$ \\
\multirow{2}{*}{ Eksperimen konfirmasi } & Rata-rata & 11.70 & $11.70 \pm 1.01$ \\
& Variabilitas (S/N) & 18.83 & $18.83 \pm 1.66$ \\
\hline
\end{tabular}

\section{Kesimpulan}

Dapat disimpulkan bahwa pemilihan level faktor kontrol terbaik untuk memperoleh karakteristik kualitas yang terbaik adalah :

- Faktor A2 (waktu roasting) $=75$ menit

- Faktor B1 (volume biji total) $=2 \mathrm{~kg}$

Dari percobaan konfirmasi didapatkan hasil bahwa terjadi penurunan sebesar 2.2 pada nilai rata-rata dari eksperimen taguchi ke eksperimen konfirmasi, dan terjadi peningkatan sebesar 5.53 pada nilai variabilitas dari eksperimen taguchi ke eksperimen konfirmasi. Karena selisih tidak terpaut jauh dan hasil ratarata serta variabilitas eksperimen taguchi dan eksperimen konfirmasinya masih dalam rentang nilai yang di- harapkan maka kombinasi faktor A2 dengan B1 terbukti dapat meningkatkan kualitas roasted bean.

\section{Daftar Pustaka}

Belavendram, N. 1995. Quality by Design, taguchi Technics for Industrial Exsperimentation, First Edition. Prentice Hall, London

Chamoli, Sunil. 2015. A Taguchi Approach for Optimization of Flow and Geometrical Parameters in A Rectangular Channel Roughened with V Down Perforated Baffles. Department of Mechanical Engineering, DIT University, Dehradun 248001. India. 
Folmer, B. 2014. How can Science help to create new value in Coffee?, Food Research International.

Schenker, S., C. Heinemann, M. Huber, R. Pompizzi, R. Perren, And F. Escher. 2002. Impact of Roasting Conditions on The Formation of Aroma Compounds in Coffee Beans. Journal of Food Science-Vol. 67, Nr. 1. Institute of Food Technologists.
Shailesh, P., Sundarrajan, S., Komaraiah, M. 2014. Optimization of Process Parameters of Al-Si Alloy by Centrifugal Casting Technique Using Taguchi Design of Experiments. 3rd International Conference on Materials Processing and Characterisation.

Soejanto, Irwan. 2009. Desain Eksperimen dengan Metode Taguchi, edisi pertama. Graha Ilmu. Yogyakarta. 